\title{
EVALUATING THE URBAN FORM OF A MOUNTAINOUS CITY FROM THE PERSPECTIVE OF COMPACTNESS CHARACTERISTICS: KIGALI CITY, RWANDA
}

\author{
Ivan RWAMPUNGU, Department of Civil Engineering and Architecture, Saga University; \\ Japan
}

Prof. Dr. Nobuo MISHIMA, Department of Civil Engineering and architecture, Saga University; Japan

\begin{abstract}
A better understanding of the composition and form of cities, and how land use changes throughout a city, can provide helpful insights for city sustainable planning. Many sustainable city models have been studied and the compact city concept has been adopted as one the sustainable model in city planning policies of many countries. However, due to dynamic nature of the city structures around the world, there exists a limited consensus on parameters and dimensions to measure urban compactness especially in the cities developed in unplanned manners. This study aims at analyzing and understanding the urban form in Kigali, the capital city of Rwanda. Two dimensions of spatial organization and spatial distribution of population were measured using GIS functions to objectively evaluate physical compactness. Findings reflected trend of decrease in compact form with absence of sustainable concepts due to lack of regularity authority control and haphazard development. Suggestive measures were provided for future consideration in sustainable urban development of the city.
\end{abstract}

\section{Keywords}

Urban form, compactness, mountainous city

\section{Introduction}

\subsection{Background}

The spatial growth of cities is an avoidable fact around the world. In the last 200 years, while the world population has increased six times, the urban population has multiplied 100 times. Today, approximately $50 \%$ of the world's population lives in urban areas (Stalker 2000). It has been very significant during last decades mainly in cities of developing counties like Asia and Africa. The expansion is caused by many factors and has been resulting in creation of different city patterns. The first and foremost reason is increase in urban population. The urban population in Africa is expected to triple by 2050 and reach 1.3 billion (UNDESA, 2014). The increase in urban population automatically lead to the increase in density and need for both living space and other activities created by the new population. The resulting spatial pattern will describe its compactness or sprawling. Some cities have been able to 
control at some extent this increase by promoting relatively high residential density, thus keeping the population inside its boundaries. On the other hand, cities have expanded its boundaries permitting the new population to live away from the city centre on green spaces leading to an unforeseen urban sprawl. A problem which is currently affecting many cities and being condemned for its negative environmental, economic and social impacts.

With these new urban forms evolving trough urban planning, many studies have tried to find out new urban forms practices and design that are sustainable. However, the debate on most suitable urban form to achieve sustainability is still unresolved. The term "Urban form" can be defined as the physical structure and pattern of urban elements meaning buildings, lots, blocks, streets, intersections, spaces and the way in which these elements are configured and used. In order to achieve urban sustainability, this combination of urban elements and the form need to be understood (Jenks 2000). Jenks, Williams and Burton included the notions of compactness, urban intensification, traditional neighbourhood design, density, mix of uses, housing type and decentralization to define a sustainable urban form. Jenks (2000).

Many sustainable city models have been studied and the compact city concept has been adopted as one the sustainable model in city planning policies of many countries. However, the compact city concept dates back to the early 1970s with the book: "Compact city: Plan for a liveable urban environment" by Dantzing and Saaty (1973). This concept resurged in the United States and later on found more attention in Europe. The rationale being to protect the city for the old compact city, the contemporary concept ensures more efficient use of the land and natural resources as well as achieving better quality of life. Moreover, the compact city concept is based on the process of intensification within city boundaries to increase residential density, centralization and mixed uses while limiting the development beyond the city boundaries (Churchman 1999). The three main components of compact city are high density, mixed land use and intensification. (Burton 2002). Many researches cleared the three components into dense and proximate development pattern, urban areas linked by public transport, and accessibility to local services and jobs. Also, UN-Habitat has recommended five principles of compactness including high density (at least 15,000 inhabitants per square kilometre), mixed land-use, social mix, limited land-use specialization, and efficient street network (UN-Habitat 2014). The benefits of compact city are such as efficient use of land while curtailing sprawl, reduction in transport network and reliance on mass transport, etc. High densities impel less space observed per capita with more land for agriculture and open spaces; public transport serve better in dense settlements with low dependence on private cars; higher densities reduce society's environmental footprint and slow the consumption of non-renewable resources (Ewing 2008).

More than half of the world's population live in urban areas and it is expected that the majority of all future urban growth will occur in Asia, Africa and Latin America. Urban populations in these three parts are expected to double by 2030, while the built-up areas of cities are expected to triple from 200.000 square kilometres to 600.000 square kilometres. (Angel et al., 2005). International policy discourses led by UN-Habitat and the world bank are thus actively exchanging new ideas and best practices on how urban planning can become effective. Within the debate on urban form, the compact city is widely promoted as a sustainable solution to the social, environmental and economic of urban sprawl and other unsustainable patterns of urbanization (UN-Habitat, 2009). However, some cities of three mentioned parts of the world may showcase difficulties to implement the concept as 
designed due to different existing composition and form of their cities (Donald B., 2017). Therefore, a better understanding of physical, social and economic characteristics, and how land use changes throughout a city can provide helpful insights for city sustainable planning.

\section{Methods}

\subsection{Case study}

Kigali is the capital, commercial and largest city of the Republic of Rwanda. It is located in the centre of the country with a status of a province, one of the five provinces in the country. Kigali is one of the fastest growing cities in Africa (Civco et al., 2005). From its inception since 1907, the city has witnessed a remarkable spatial expansion, population growth and developmental activities such as building, road construction, deforestation and many other anthropogenic activities (REMA, 2013). In 1991, Kigali city only covered an area of $112 \mathrm{~km} 2$ with 140,000 inhabitants. In 2012, the city expanded to a total population of 1,135,428 living in an area of $730 \mathrm{~km} 2$ (NISR, 2012). This has resulted in increased land consumption and a modification and alterations in the status of land cover/use (REMA, 2013).

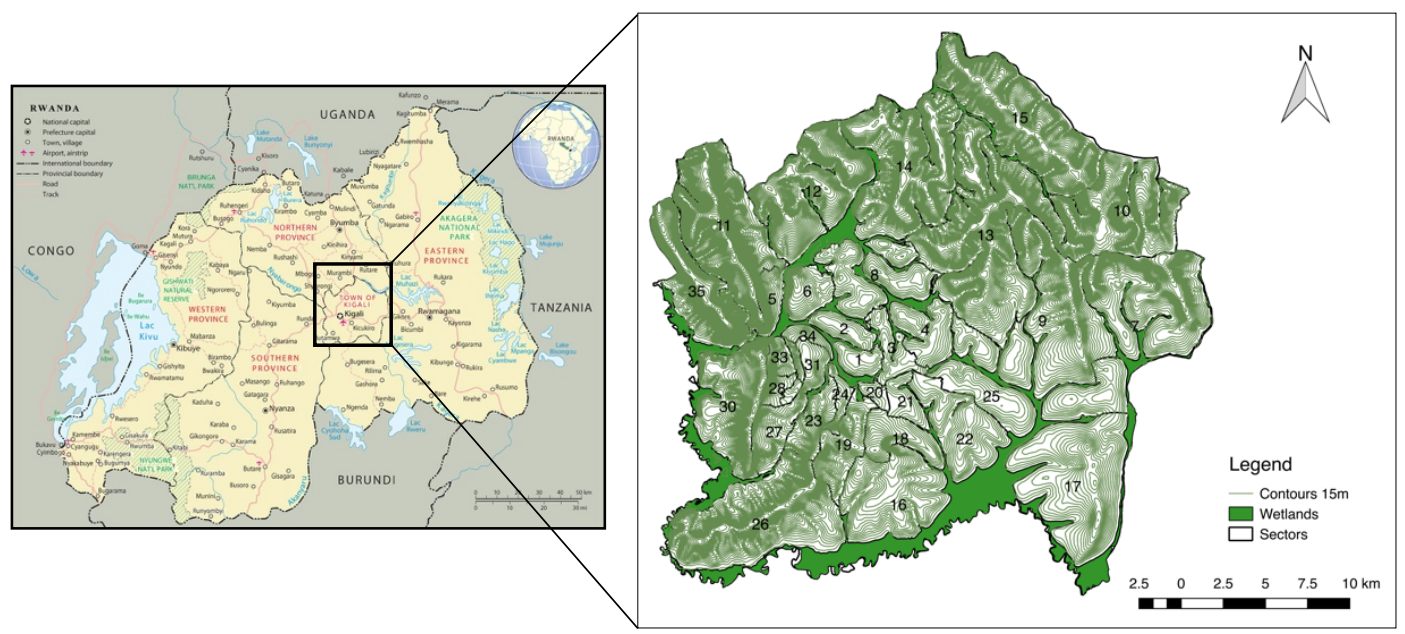

Figure 1 Location of Kigali City and its topographic features. Source:

Kigali is built in hilly landscapes sprawling across ridges and wet valleys in between. Big structures like universities, banks, hotels, international organizations, embassies, government offices, commercial buildings and residential areas of affluent people tend to be built on top of the ridges while the poorer people live down towards the valley. Other poor neighbourhoods are located on the hills which can be seen in the fringes of the city. Wetlands, water bodies, forests, hills with slopes greater than $20 \%$ and other natural constraints to development cover about $50 \%$ of Kigali's area. The city is administratively divided into 3 districts and 35 sub-districts or sectors.

\subsection{Aim and objectives}

The aim of this study is to measure the urban form of Kigali city, Rwanda through various characteristics of compact form as a sustainable form. The objectives are: (1) to explore trends of urban form expansion; (2) to analyse and evaluate the existing urban form through spatial organization and population distribution measurements and find out whether Kigali city expansion trend generate a compact form, favourable to achieve sustainable urban development. 


\subsection{Urban form, Compact form and measuring approaches}

Urban form is a spatial composition of elements that repeat, and if based on certain sustainable concepts, can lead to the sustainability of cities. The urban form can be monitored on different levels from individual building, street, urban block, neighbourhood to city level (Bertaud, 2013). It is characterized by physical and non-physical characteristics. The physical characteristics are usually stable and easily measurable while non-physical such as density are dynamic. The compact form is conceptually and arguably takin as a sustainable form. Its concept is based on various principles such as intensification, density and mix of uses. This study mainly relates the urban form to the spatial organization and distribution of the population, and land use change trends from natural areas to urban built-up areas. Density and its spatial distribution are basic component of urban form and is used widely for sprawl assessments. Reduction in density over time is considered an indication of urban sprawl and density distribution defines the compactness of urban form.

\subsection{Data collection}

Data was collected from various government institutions. Various literatures were also reviewed in order to understand spatial organization of urban form and distributions of population. GIS maps representing land use in various year were directly corrected from the urban planning department of the City of Kigali and other data such wetlands data and population census were retrieved from official websites of respective governments institutions. This study is limited to year 2013 due to the availability of data.

\subsection{Proposed methodology}

Various measures of urban form and compact form are developed by researchers and mainly focus of different aspects such impact of urban form on social, economic, environmental or transport behaviour. In this study, several literatures were reviewed to identify common parameters (Fig.2) that can allow to measure the urban form. In this study, the analysis focused on the spatial organization and spatial distribution of the population. Moreover, some parameters were discussed through literature review and the Kigali Master Plan 2050 which was put in place in 2010.

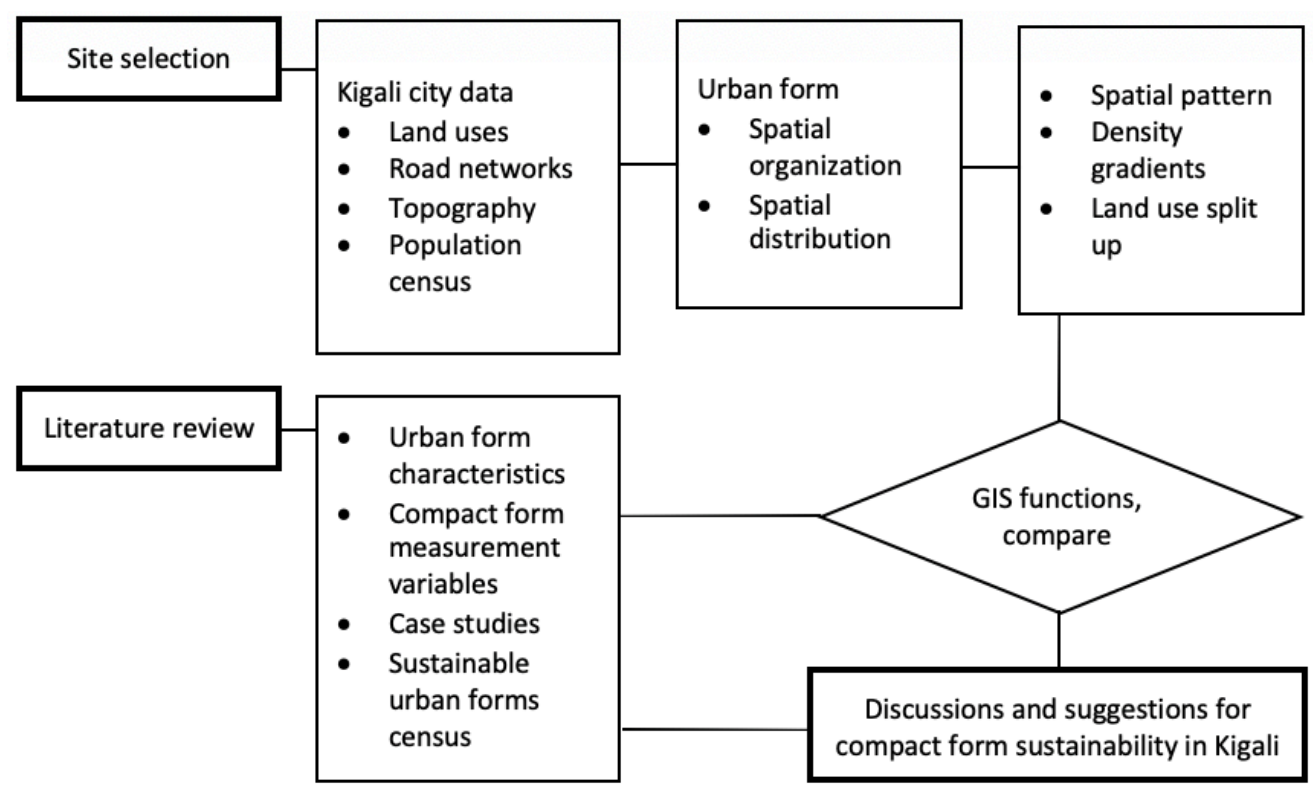

Figure 2 Analysis method. Diagram developed by author 


\section{Data interpretation}

\subsection{Spatial organization}

The city of Kigali was founded in 1907 but its urban growth started in 1962 after it was declared the capital city. In order to understand the spatial organization of the city we used the method of Bertaud (Bertaud A., 2013). The method uses the concept of superimposing two patterns of the city (1) the spatial pattern of population distribution within the city's built up area when people are at home and (2) the pattern of movement people make around the city during the day. The city of Kigali was found to be predominantly a monocentric model with a dominant $C B D$ and sub-centres. This is mainly a consequence of topography constraints. The CBD, which is taken as the starting point of the city, is located on the top of a hill with gentle slopes and surrounded by wetlands in the northern, eastern and southern sides. On the other hand, the western side is obstructed by mountains with steep slopes. In the process of urbanization, new large to small scale sub-centres were developed creating a multi-centre development with simultaneous radial and random movements of people across the city.

The Central Business District (CBD) is located $6 \mathrm{~km}$ (Fig. 3) in the western direction from the centre of gravity (CG). The city spatial expansion was always directed to the east. While the eastern part of the city showcases gentler slope, the western part of the CBD is obstructed by Mount Kigali. As par the organic law of the Kigali Master Plan, the developable land should have a slope of less than 20 per cent (KMP, 2013). However, as the master was put in place in 2010, many settlements are located on steep slopes, thus in risky zones to be relocated. Therefore, the spatial distribution and expansion of the city has been mainly influenced by topographical challenges.

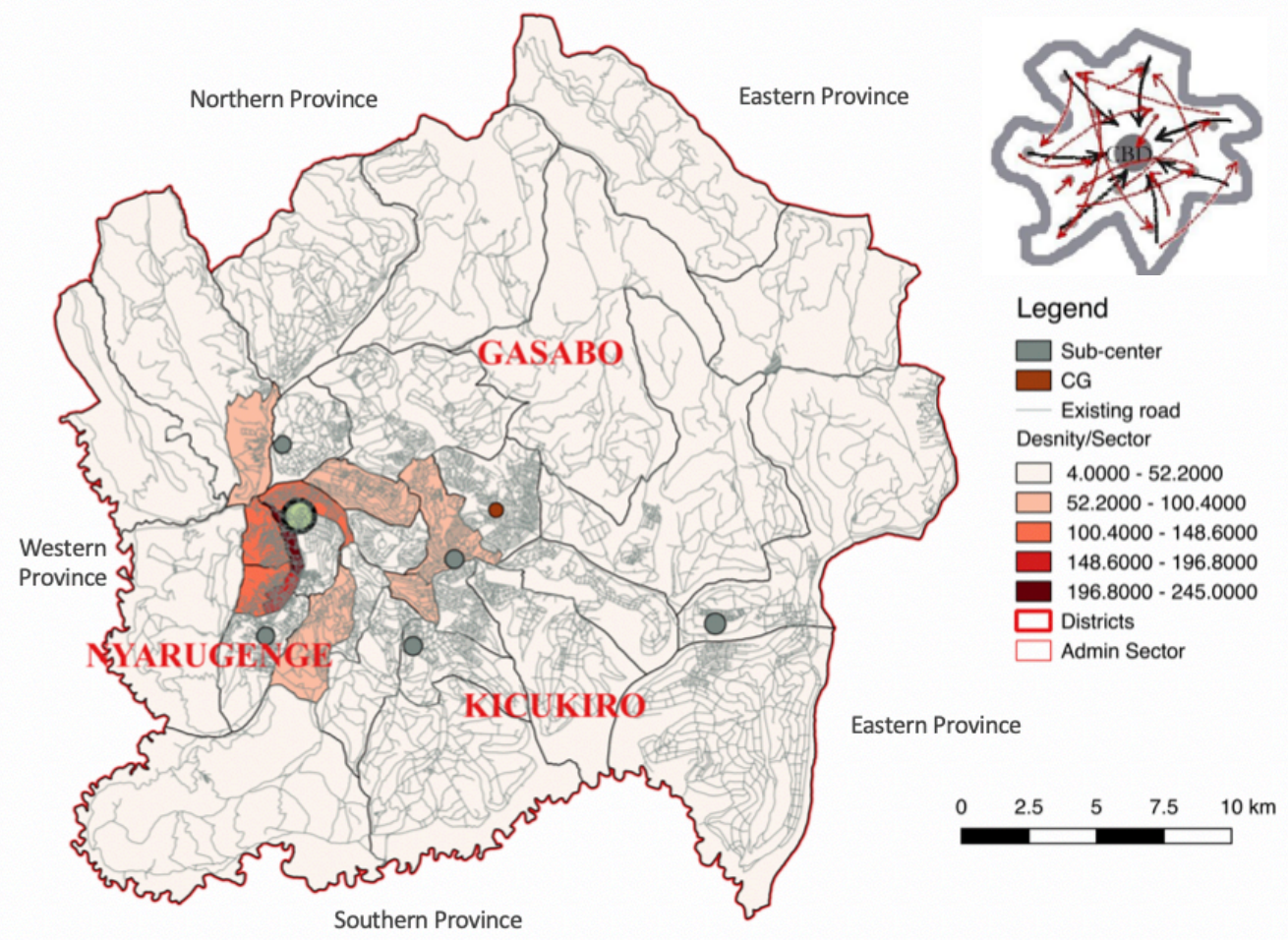

Figure 3 CBD eccentricity and topographical challenges. (Data source: Kigali city urban planning department) 


\subsection{Spatial distribution}

The spatial distribution of the city was analysed through density indicators. The calculations should be based on the built-up area. Four indicators are measured: (1) Average built up area density, (2) Land use split up, (3) Density profile and (4) Population by distance to CBD.
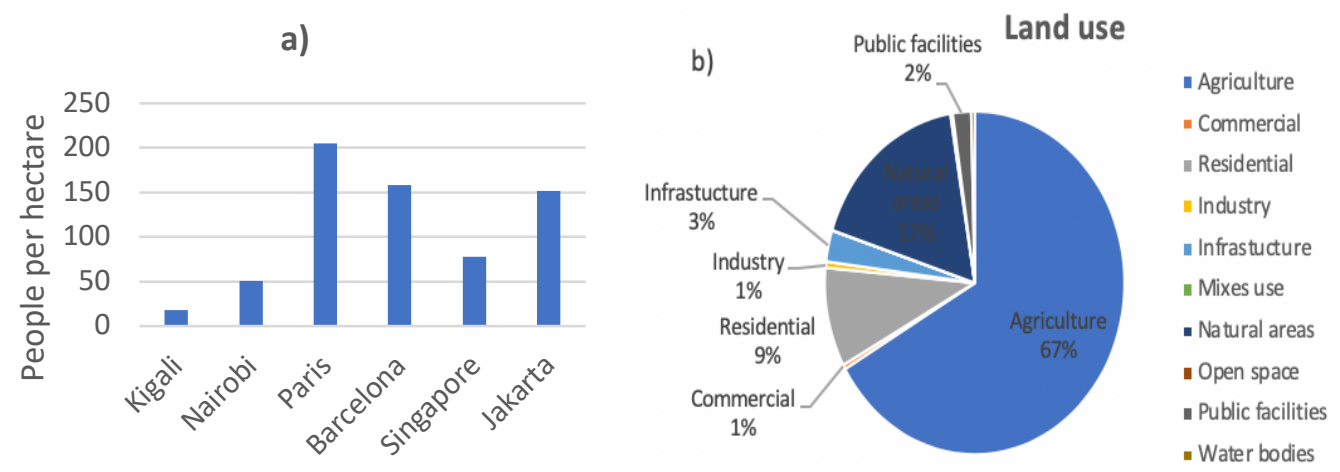

Figure 4 a) Density based on administrative boundaries, b) Land use of Kigali City (2013). (Source: a) Population and area numbers from http://citypopulation.de/, calculations done by author. b) RNRA, 2012)

Figure 4.a illustrates densities of various cities based on their administrative boundaries. As it is visible the density of Kigali is very low compared to other cities. Cities like Barcelona and Paris are classified as compact city due to various reasons including their densification. Figure 4.b showcases the land use occupation in Kigali city in year 2013.

\subsubsection{Built up area density}

The urban built-up area of Kigali has been growing rapidly since 1962, when it was declared the capital city of Rwanda. In 1990, the administrative area of Kigali was $112 \mathrm{Km} 2$ with 21 $\mathrm{Km} 2$ of built up area. Later in 2000, the total area was increased to $349 \mathrm{Km} 2$ with an increase to $47 \mathrm{Km} 2$ of built-up area. It is after 2006 administrative reforms, that the boundaries were expanded to $730 \mathrm{Km} 2$.

In general, the city experienced a relative expansion of built-up areas. Between 1990 and 2010, the city showcases more compactness in the CBD and surrounding built-up areas. The built-up area density has been increasing constantly to reach 147 people per hectare (Figure 5). From 1990 to 2000, the density was primary supported by the densification around the CBD while between 2000 and 2010, however the city area was expanding, the city continued to showcase some more compactness due to a high rate of urban migration compared to settlements. In 2010, the city become more sprawled as the urban density started decreasing. There was a remarkable extension trend in all sides of the city except the western part as depicted in Figure 6. However, the tendency is higher in the eastern and northern sides. The western side was spared to its topography critical for built-up and forests cover.

Furthermore, some new built-up areas appeared in the hinterland of the Southern part. These are smaller and dispersed built-up patches compared to the Northern and Eastern development. Rural lands have been converted into built-up areas due to the increase in urban activities (REMA, 2013). There is a big demand for land by the high number of offices, schools, industries built during last 27years. Moreover, citizens constructed bungalows instead of high-rise apartments. 


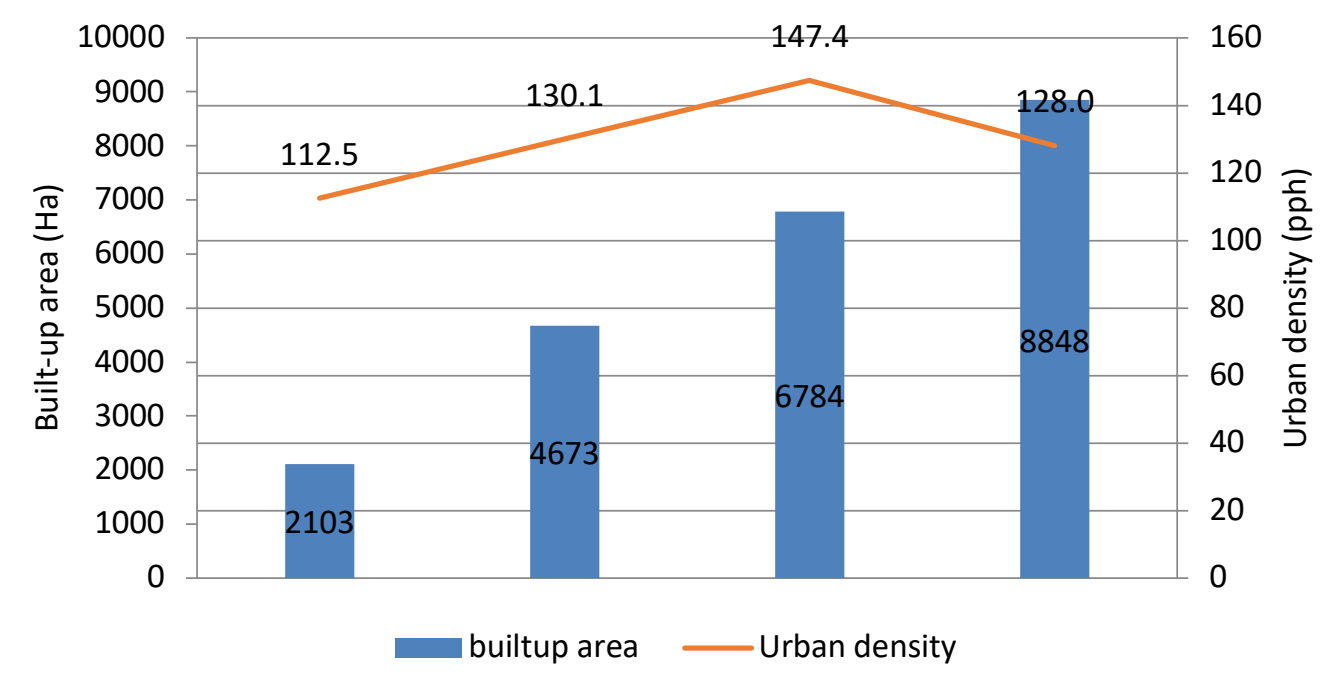

Figure 5 Built up expansion trends from 1990-2013. (Source: Based on KCMP, 2013)

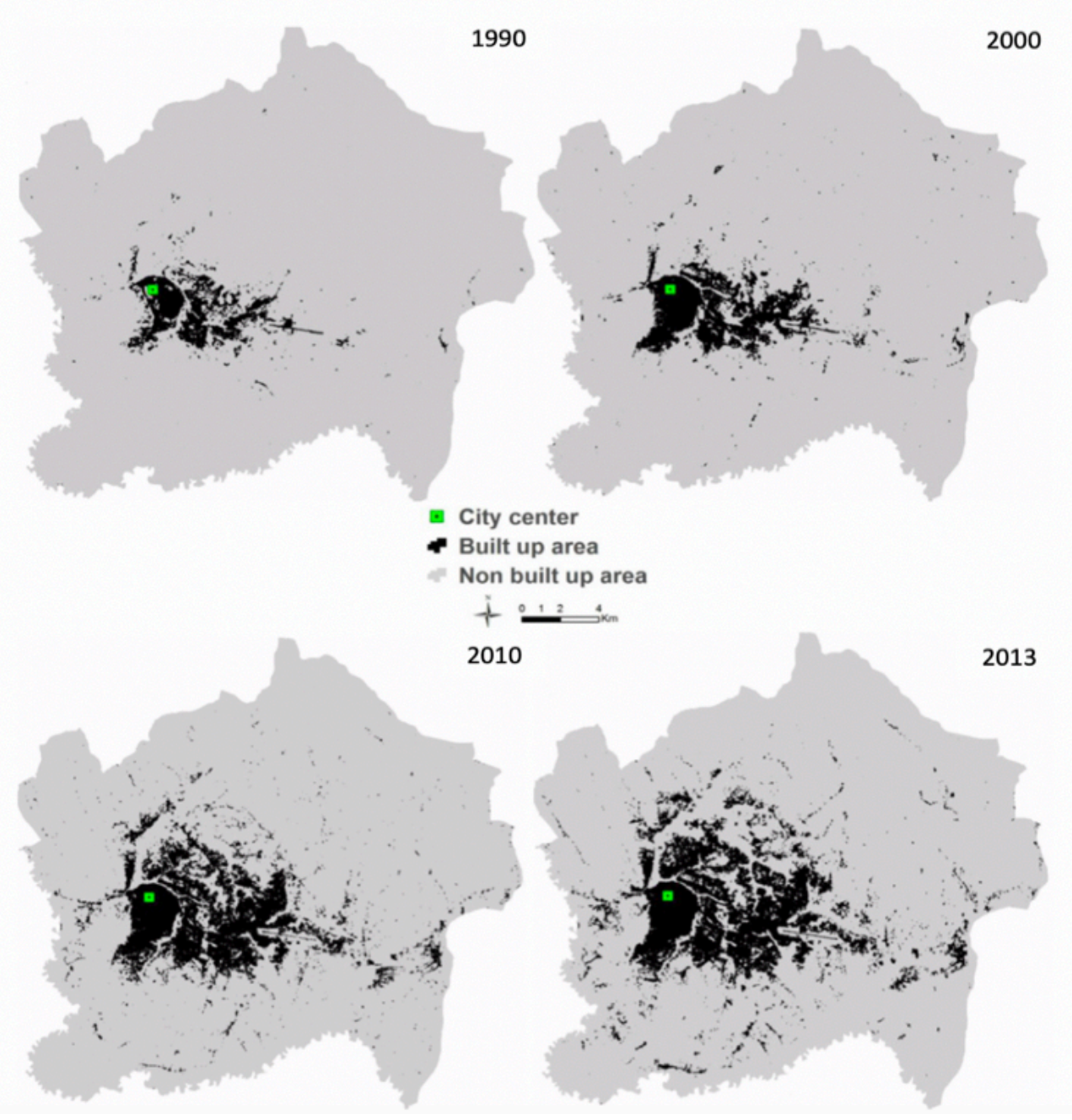

Figure 6 Built up expansion trends from 1990-2013. (Data source: Kigali City Urban planning department) 


\subsubsection{Land Use split up}

The urban land composition has undergone series of land use changes since 1990. As shown Table 1, in 1990, only $2.9 \%$ of the total current area of the city was built-up. The agriculture land which includes all green space natural forests excluded, as they are counted in the category of natural areas together with wetlands, has been decreasing with a high decrease during 2001 and 2010. However, the 5.5\% decrease in agriculture land was expanded during the 10 years while between 2010 and 2013, only 3 years, a 4.5\% decrease is recorded. Although, this category experienced changes and decrease, by 2013 , it represented $67 \%$ of the total land use. The land used for agriculture is sometimes on steep slopes where any development is typically impossible, thus making it the major land use category within the city.

The built-up area recorded a $341.7 \%$ increase over 23 years since 1990 . Within the first decade only, the built-up area doubled. The causes are many including the social events such as the end to the genocide in 1994 with many people coming back to settle in the capital as a safer place compared to the surroundings provinces. Although the change rate reduced since 2000, the built-up area is still increasing from changes of other land use categories mainly the agriculture land. A remarkable increase in land used for infrastructure is also noticed during the first and second decades. This is particularly the effect of development and settlement whereby infrastructures such as roads are built to connect different zones of the city.

\begin{tabular}{lllll|llll}
\hline $\begin{array}{l}\text { Land } \\
\text { name }\end{array}$ & \multicolumn{3}{c|}{ Land use (in Ha) } & \multicolumn{4}{c}{ Net change (in \%) } \\
\cline { 2 - 9 } & $\mathbf{1 9 9 0}$ & $\mathbf{2 0 0 0}$ & $\mathbf{2 0 1 0}$ & $\mathbf{2 0 1 3}$ & $\mathbf{1 9 9 0}$ & $\mathbf{2 0 0 1 -}$ & $\mathbf{2 0 1 1}-$ & $\mathbf{1 9 9 0 -}$ \\
& & & & & $\mathbf{2 0 0 0}$ & $\mathbf{2 0 1 0}$ & $\mathbf{2 0 1 3}$ & $\mathbf{2 0 1 3}$ \\
\hline Agriculture & 53789 & 52905 & 49986 & 47755 & -1.6 & -5.5 & -4.5 & -11.2 \\
Built-up & 2103 & 4673 & 6784 & 9288 & 122.2 & 45.2 & 36.9 & 341.7 \\
Water Bodies & 132 & 132 & 285 & 283 & 0.0 & 115.9 & -0.7 & 114.4 \\
Infrastructure & 465 & 1238 & 2434 & 2915 & 166.2 & 96.6 & 19.8 & 526.9 \\
Natural areas & 13995 & 11526 & 10975 & 12658 & -17.4 & -4.8 & 15.4 & -9.5 \\
\hline
\end{tabular}

Figure 7 Land use changes in 1990, 2000, 2010 and 2013. (Data source: RNRA, 2012)

In 2013 , the built-up area composed $13 \%$ of the total area and $18 \%$ of the total developable area (not steep slopes or wetlands). As shown in Figure 8 within the built-up area, 67 hectares $(76 \%)$ are occupied by residential houses mainly scattered and unplanned followed by 14 hectares (16\%) occupied by public facilities, 4 hectares (5\%) by industries, 3 hectares (3\%) by commercial buildings and a relatively small percentage of mixed-use development. On the other hand, public urban open spaces such as squares or parks are almost nonexistent in the city. Few roundabouts are sometimes used as public open space. There is need to avail more land for recreational purposes. The Kigali Master Plan 2050 proposed developing and converting wetlands into recreational parks and gardens, thus proving more open spaces while also protecting the environment. Some of the wetlands are currently being occupied by unplanned settlements such as residential buildings or often commercial activities such as car washes. 


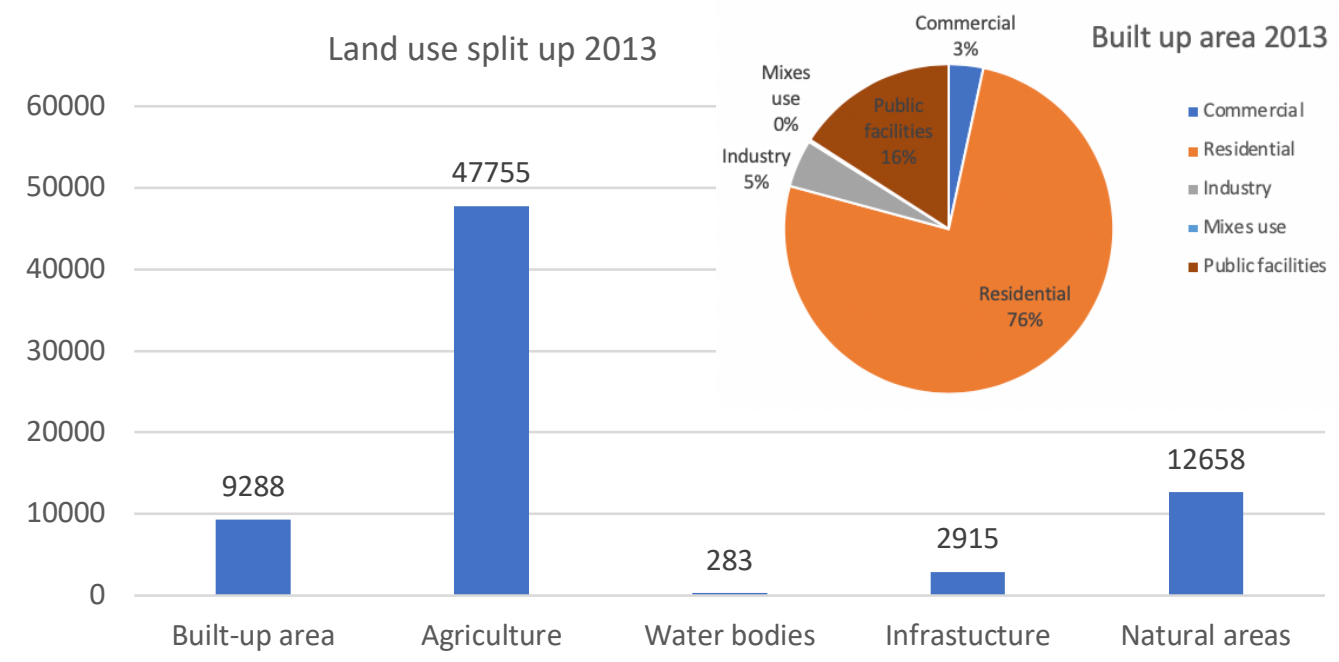

Figure 8 Land use-split up in 2013. (Data source: RNRA, 2012)

\subsubsection{Population by distance to CBD/CG}

Figure 9 illustrates the population densities residing within a certain distance to the CBD for the year 1990, 2000, 2010 and 2013. IN 2013, the high densities can be noticed near the CBD as they tumble down when going far of the CBD. Within $2 \mathrm{~km}$ radius of the $C B D$, the densities are nearly 100 people by hectare. After $5 \mathrm{~km}$, the densities are less than 20 people by hectare and remain almost constant. The CBD is located $6 \mathrm{~km}$ from the western boundary of the city, thus the only the population in the eastern direction is counted.

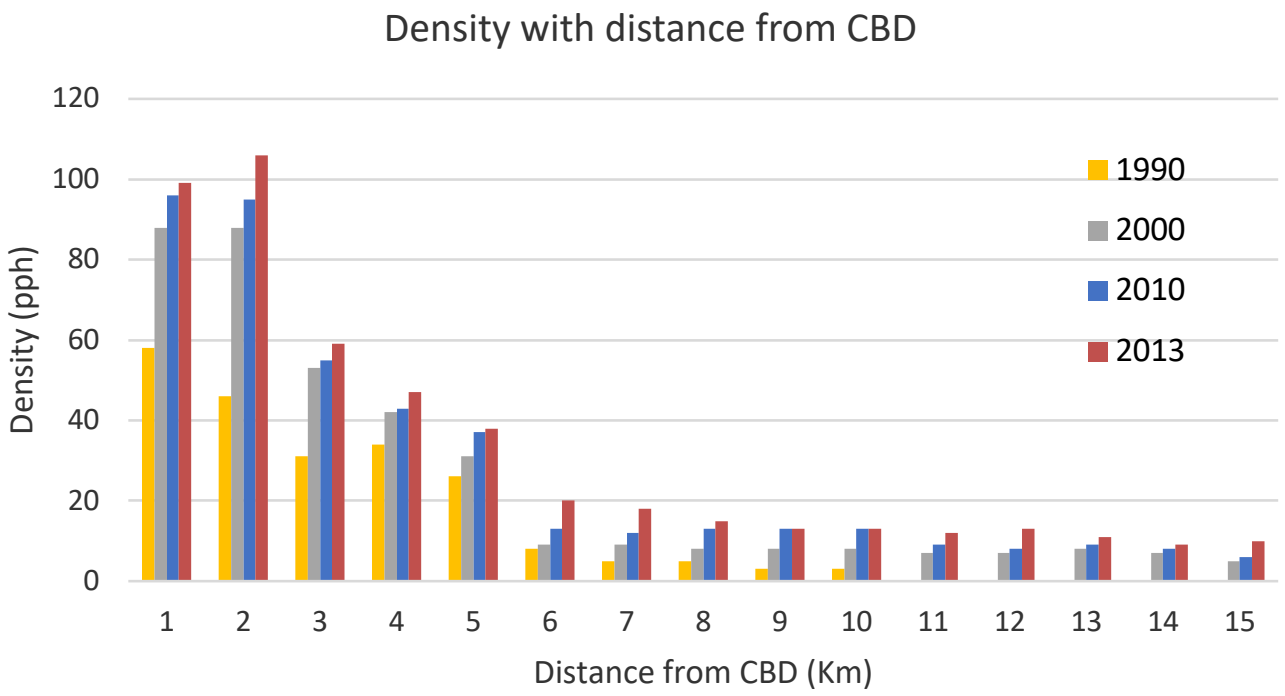

Figure 9 Density variations with distance from CBD. (Data source: RNRA, 2012)

Figure 9 is showing how residential area is spread with distance from the CBD. Despite high densities presents around the CBD, Regular residential land is consistently spread throughout the city. Likewise, as one leaves the city center and moves towards the periphery commercial/industrial land tapers off but does not disappear. This is probably due to the fact that Kigali has no large industrial zone. 


\section{Discussions}

Kigali city is dominantly a monocentric city with various sub-centres spread over the city. The CBD eccentricity is located $6 \mathrm{~km}$ from the supposedly centre of Gravity of the city. The spatial growth of the city has been observed directed in the eastern part while in the western part, the expansion is obstructed by steep slopes typically impossible for development. As cited by the law, no development is allowed on slope exceeding 20 per cent. The eccentricity of the city is due to the first modern settlements after the colonization on the top of the hill to ensure security. As the city developed, other commercial services also joined creating the CBD near settlements.

Kigali city showcased an increase in urban built-up area corresponding to its growth of population. From 1990 to 2010, the city has been increasing its urban density creating a more compact city. This was mainly due to intensification of areas surrounding the CBD, whereby in some places, densities exceed 200 people per hectare. With a large percentage of these densities coming from unplanned settlements and eventually located in high risk zones with steep slopes or wetlands. In 2010, the urban density was 147 people per hectare, a value that can be related to that one recommended by UN-Habitat as 150 people per hectare. After 2010, the urban density started decreasing and this is explained by the increase of land consumption, a sign of city sprawl. Kigali population is growing on a rate $4 \%$ per annum (2000-2013) and the population is expected to double in 2025 (KCMP, 2013). This increase in urban population has placed considerable pressure on Kigali's housing stock, and resulted in the construction of informal settlements. To meet projected housing demands, Kigali would need to construct roughly 344,000 formal housing units by 2022, but currently less than 1,000 are constructed annually (City of Kigali, 20123).

Kigali city has limited mixed land. Only 19 hectares, representing almost zero percent of built up land, were classified as mixed land use. The biggest percentage with $67 \%$ of the total land use is the Agriculture lands. They are followed by natural areas, consisted of natural forests and wetlands, with $17 \%$ and built up areas with $13 \%$. Infrastructures are apart with $4 \%$ of the total city area. Within the built-up area, $76 \%$ is consumed by residential areas, $16 \%$ by public facilities, $5 \%$ by commercial areas and $3 \%$ of the total built-up areas by industries or industrial zones. Although the city is considered green, due to green areas across streets and other areas, only 12 hectares are dedicated to urban open spaces such as parks and gardens. Presently, much of the agriculture land and forest cover is encroached upon and developed as built-up residential sprawl. Since 2010, the built-up densities started decreasing, thus leading to a sprawl tendency. One of the reasons being that since the implementation of the Kigali Master Plan, illegal developments were stopped and policies were adopted making difficult for unplanned settlements. Therefore, land prices in the urban areas started increasing and people objected for settling in the close suburbs whereby land is available on low prices.

The decrease in density as the distance from the CBD increases is a characteristic of the monocentric form of the city. While within 2 kilometres from the CBD, densities are relatively high, there is a detectable drop of density after. On one hand, it can be explained that, the urban built-up area on the western part of the CBD is discontinuous due to topography challenges. Very few developments were made on the steep slopes of mountains located at $2 \mathrm{~km}$ western side of the CBD. It is noticeable, that after $5 \mathrm{~km}$ from the $\mathrm{CBD}$, the density is slightly decreasing. These are new settlements which mainly happened 
after the adoption and implementation of the Kigali Master Plan in 2010. They are planned low residential settlements located along main national roads, and they contribute meaningfully in sprawl of the city. Additionally, sub-centres have been created by these settlements.

\section{Conclusion and future research}

The study illustrated the trends of urban form in different years while understanding whether the city is developing a compact form. To understand it we used two dimensions of urban form which are spatial organization and spatial distribution of the population. Three variables of the spatial distribution were discussed. Furthermore, discussions were related to other compact cities to understand future urban form of Kigali City. Following this study, analysis of spatial organization and density distribution shows that Kigali is dominated by a monocentric compact form which grow in a polycentric dispersing form. In other words, the city compact form is dispersing creating new low densities. The compact form present early was facilitating shorter travels and higher densities within the CBD and its surroundings. Thus, it is necessary to increase density in new sub centres to sustain a more compact form. However, increasing density alone without infrastructure improvement may lead to an adverse impact on sustainability. To achieve a more compact city form, infrastructure upgrade and provision of more amenities and other facilities such as recreational parks, together with transport network is very necessary. An intensification through high density development in existing urban areas and sub centres may lead the city to a compact city.

Though, there is a high consideration of Kigali Master plan, its implementation should consider the trends of city expansion and better urban management, administration and strict regulations are necessary to achieve a more compact form with its benefits. Inclusive planning with more involvement and participation of people in the panning and implementation processes is extremely important and should be adopted to cater for economic and social needs. The existing high percentage of informal development should also be considered as it affects the success of compact city. There is also need to avail more land for recreational purposes and mixed land uses development promotion through various zoning of the city. While the compact city model has been adopted and applied as sustainable model mainly in cities of developed countries, this study suggest that such analysis can be useful for understanding the spatial structure and evolution of the city and thus in future planning and adoption of the compact city policies implementation.

Future research will be focusing on modelling and simulation of future compact urban form basing on trends and characteristics of the existing spatial organization and population distribution. Models may contribute in future urban planning and Kigali Master Plan implementation assessment.

\section{Acknowledgements}

This work was supported by the Japanese International Cooperation Agency (JICA) through $A B E$ Initiative Scholarship. The authors would like to acknowledge the support and facilitation by the Urban planning department of the city of Kigali to provide part of the data used in this study. 


\section{References}

Angel, Shlomo; Sheppard, Stephen; Civco, Daniel (2005) The Dynamics of global urban expansion. Washington, DC.; Transport and urban development department, the World Bank.

Bertaud, Alain (2013) Metropolis: A measure of the spatial organization of 7 large cities.

Burton, Elizabeth (2002) Measuring urban compactness in UK towns and cities. Environment and Planning B: Planning and Design 29(2): 219:250.

City of Kigali (2012) The Kigali Housing market brochure,

Civco, Daniel; Sheppard, Stephen. The urban growth management initiative: Confronting the expected doubling of the size of cities in the developing countries in the next thirty years-methods and preliminary results. ASPRS 2005 Annual conference

Churchman, Arza (1999) Disentangling the concept of density. Journal of Planning Literature 13(4): 389-411.

Donald Brown (2017) Challenging the conceptual boundaries of the compact city paradigm in sub-Saharan Africa: Towards southern Alternatives. DPU The Bartlett: London UK.

Ewing, Reid (2008) Characteristics, causes and effects of Sprawl. A literature review.

Jenks, Mike; Williams, Katie; Burton; Elizabeth (1996). The compact city: A sustainable urban form? Chapman and Hall: London, UK.

Jenks, Mike; Williams, Katie; Burton, Elizabeth (2000). Achieving sustainable urban form; E\&FN Spon: London, UK.

Kigali City Master Plan. (2013). Analysis, benchmarking and vision report. City of Kigali.

National Institute of Statistics of Rwanda. (2012). Population and Housing Census, Kigali.

Rwanda Environment Management Authority. (2013). Kigali State of environment and outlook report.

Rwanda Natural Resources Authority. (2012). Rwanda National Land Use development master plan 2010-2020.

Stalker, Peter (2000) Handbook of World. Oxford University Press, New York.

UNDESA (2014) World urbanization prospects: The 2014, CD-ROM edition.

UN-Habitat (2014) A new strategy of sustainable neighborhood planning: five principles.

Urban discussions Note 3. Retrieved from https:/unhabitat.org/wp-

content/uploads/2014/05/5-Principles_web.pdf.

UN-Habitat (2009) Global report on human settlement: Planning sustainable cities. London: Earthscan.

World bank (2010) Eco2 cities: ecological cities as economic cities. The World Bank. 